
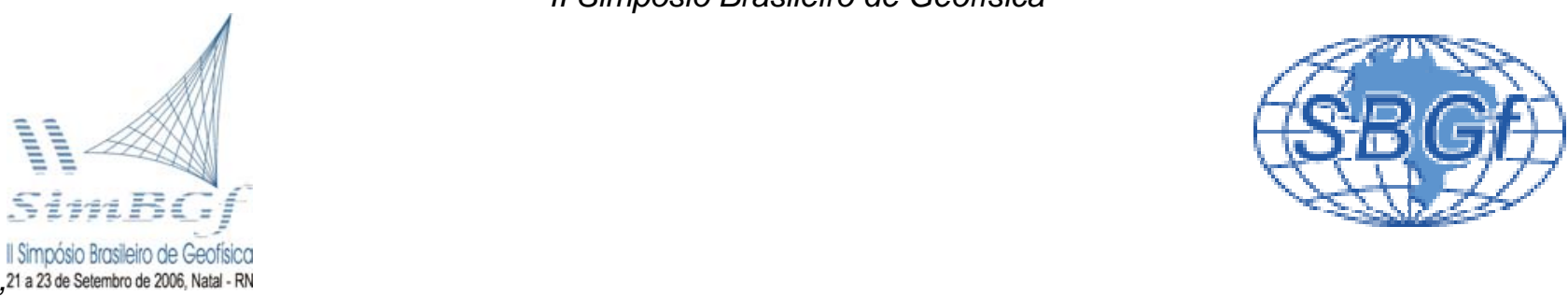

\title{
ANÁLISE QUALITATIVA DA ANISOTROPIA DE MACIÇOS GEOLÓGICOS ATRAVÉS DA SEÇÃO DE CONVOLUÇÃO DE DADOS DE SÍSMICA DE REFRAÇÃO RASA
}

Ricardo Felipe Chartuni Cabral da Cruz

Renato Luiz Prado, IAG-USP

Copyright 2006, SBGf - Sociedade Brasileira de Geofísica

Este texto foi preparado para a apresentação no II Simpósio de Geofísica da Sociedade Brasileira de Geofísica, Natal, 21-23 de setembro de 2006. Seu conteúdo foi revisado pela Comissão Tecno-científica do II SimBGf mas não necessariamente representa a opinião da SBGf ou de seus associados. E proibida a reprodução total ou parcial deste material para propósitos comerciais sem prévia autorização da SBGf.

\section{Resumo}

Este trabalho apresenta resultados preliminares de estudos de modelagem e de ensaio de campo empregando a técnica RCS (Refraction Convolution Section) visando à identificação de anisotropia de maciço geológico através da análise das amplitudes dos eventos relacionadas às ondas frontais.

Os ensaios de campo foram realizados em área de afloramento de falha transcorrente com pronunciada estrutura subvertical.

Os resultados obtidos tanto nos dados sintéticos quanto nos de campo demonstram que o método é rápido e robusto, revelando além das feições estruturais do refrator suas características geológicas.

\section{Introdução}

Pode-se dizer que a sísmica de refração rasa apresentou nas últimas décadas poucos avanços se comparados aos significativos progressos experimentados pela sísmica de reflexão. Essa diferença se deve principalmente ao fato da sísmica de refração rasa estar mais ligada às áreas de engenharia e geotecnia, muito focadas na minimização de custos e no estabelecimento de procedimentos padrão.

Recentemente Palmer (2001) apresentou resultados interessantes do que chamou Seção de Convolução da Refração (Refraction Convolution Section - RCS), gerada a partir da convolução dos traços sísmicos dos tiros direto e reverso obtidos em ensaios convencionais de sísmica de refração rasa.

A seção de convolução, semelhante à seção empilhada e migrada da sísmica de reflexão, apresenta as feições estruturais do refrator e permite relacionar as variações de amplitude das ondas frontais às características geológicas do refrator.

A possibilidade de se agregar aos resultados convencionais da sísmica de refração (i.e., profundidades do refrator) atributos do traço sísmico (variações de amplitude) que trazem informações adicionais quanto às suas características geológicas é aspecto altamente inovador e importante para a técnica.

Neste trabalho são apresentados resultados preliminares de estudos de modelagem e ensaio de campo empregando a técnica RCS visando à identificação de anisotropia de maciço.

\section{Metodologia}

O processo de convolução é usualmente associado com filtros. No domínio da freqüência esse processo é descrito como a multiplicação dos espectros de amplitude e adição dos espectros de fase de duas funções.

Resultado similar se busca com a convolução de dois traços da sísmica de refração. Neste caso os tempos de chegada das ondas refratadas, que estão contidos dentro do espectro de fase, são adicionados.

Isto pode ser demonstrado através da transformada z. O traço sísmico digitalizado pode ser representado como um polinômio em $z$, cujos expoentes representam o número da amostra. Assim, para o traço direto podemos escrever:

$$
D(z)=d_{m} z^{m}+d_{m+1} z^{m+1}+d_{m+2} z^{m+2}+\ldots .
$$

onde $d_{j}=0$ para $j<m$

O tempo de trajetória do raio direto é $m$, uma vez que $d_{m}$ é a primeira amplitude diferente de zero do traço digitalizado e, portanto, representa o início da chegada da energia sísmica.

Da mesma forma, para o traço do raio reverso temos:

$$
R(z)=r_{n} z^{n}+r_{n+1} z^{n+1}+r_{n+2} z^{n+2}+\ldots
$$

onde $r_{j}=0$ para $j<n$

A convolução no domínio z resulta em:

$$
\begin{aligned}
& D(z) * R(z)=d_{m} r_{n} z^{m+n}+\left(d_{m} r_{n+1}+d_{m+1} r_{n}\right) z^{m+n+1}+ \\
& +\left(d_{m} r_{n+2}+d_{m+1} r_{n+1}+d_{m+2} r_{n}\right) z^{m+n+2}+\ldots
\end{aligned}
$$

Verifica-se que o primeiro coeficiente diferente de zero será $d_{m} r_{n}$ e ocorre no tempo $m+n$, que é a soma dos tempos de trajetória dos raios direto e reverso.

Nesse processo o sobretempo (moveout) é removido e a seção final apresentará a mesma estrutura do refrator. Além disso, no processo de multiplicação dos espectros de amplitude há também a compensação das grandes 
variações de amplitude originadas principalmente pelo espalhamento geométrico. Essa compensação é geralmente suficiente para reconhecer variações de amplitude relacionadas às feições geológicas.

Primeiramente foram realizados estudos com dados sintéticos obtidos de modelos geológicos que apresentavam variação lateral de profundidade e velocidade da interface refratora principal.

Após esses estudos foram realizados ensaios de campo em afloramento de importante zona de falha transcorrente presente na cidade de São Paulo e região próxima, a falha de Taxaquara, com execução de perfis concordantes e discordantes a sua estruturação.

\section{Resultados e discussões}

Para a obtenção dos tempos de percurso sintéticos das primeiras chegadas das ondas refratadas utilizou-se 0 aplicativo Reflex-Win v.3.5.7 depois da definição de um modelo geológico bi-dimensional (Figura 1). O método empregado é baseado em aproximações por diferenças finitas da equação eikonal e considera a existência de ondas transmitidas, difratadas e frontais.

Para a obtenção dos valores das amplitudes utilizou-se a expressão apresentada em Werth (1967):

$A=\frac{K \cdot F(t)}{\sqrt{r \cdot L^{3}}}$

onde $K$ é o chamado head coefficient, que depende das propriedades elásticas das camadas superior e inferior; $F(t)$ é o potencial de deslocamento do pulso incidente, $r$ é a distância fonte-receptor e $L$ é a distância que a onda viajou dentro do refrator.

Integrando-se as amplitudes e os tempos de percurso obtidos chegou-se aos sismogramas sintéticos (tiros direto e reverso), que convolvidos geraram a seção RCS (Figura 2).

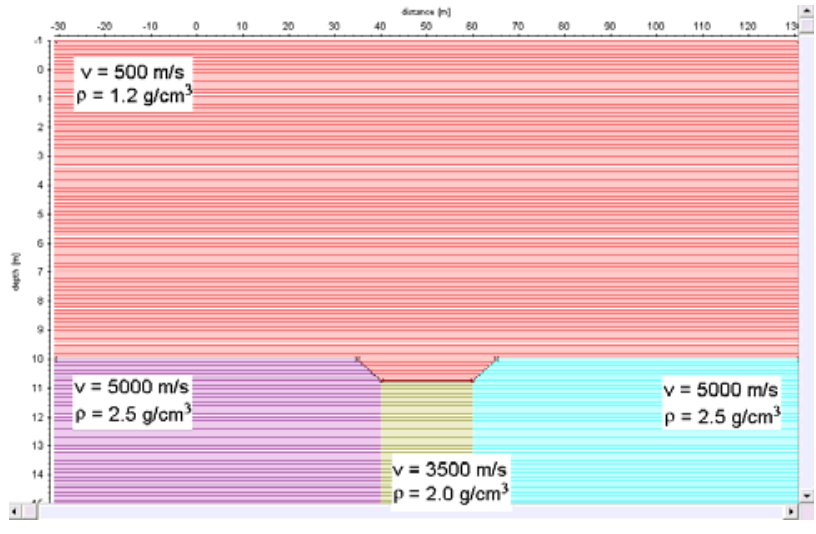

Figura 1: Modelo geológico escolhido para geração dos sismogramas sintéticos.

As seções RCS e a obtida pelo método recíproco GRM, muito empregado na análise de dados de refração rasa (não apresentada neste trabalho), reproduziram a mesma estrutura do modelo geológico proposto, porém a primeira foi gerada automaticamente pela simples convolução dos traços dos tiros direto e reverso.
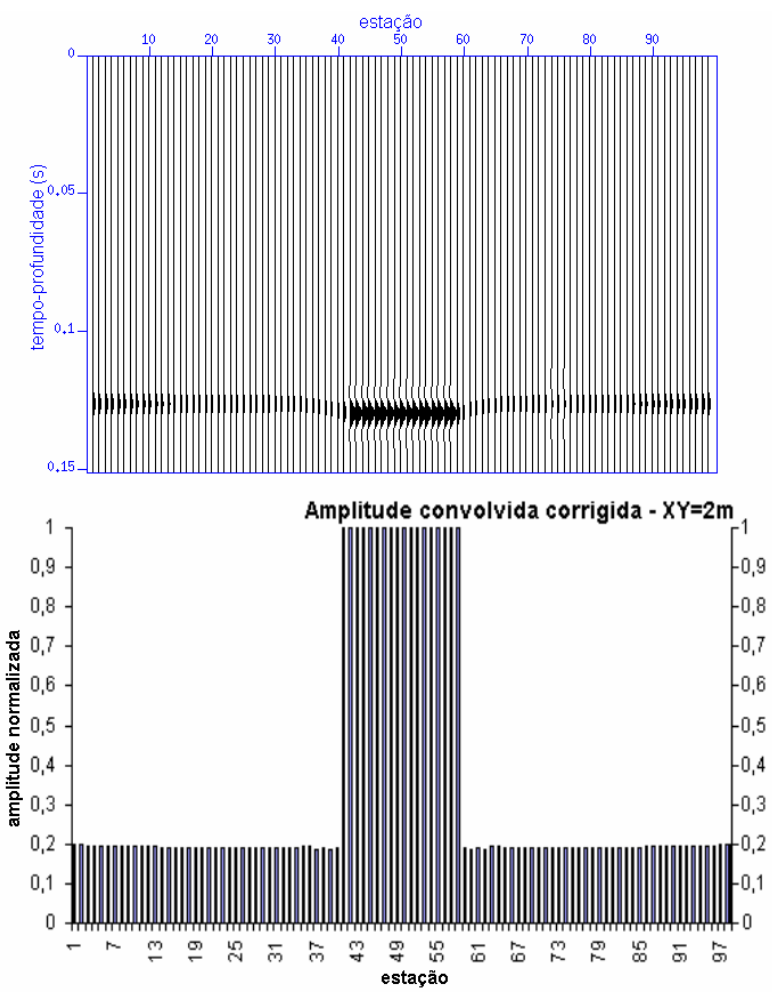

Figura 2: Sismograma da seção de convolução (a) e gráfico das amplitudes normalizadas dos traços convolvidos corrigidas pelo fator do espalhamento geométrico (b).

Observa-se, claramente, na Figura 2 um contraste de amplitudes (estações 41 a 55) relacionado a mudança lateral de propriedades petrofísicas do refrator, no caso mudanças de velocidade e densidade (head coefficient da equação 4), como simulado pelo modelo geológico proposto.

Os ensaios de campo foram realizados em afloramento de rochas cataclásticas associadas ao importante falhamento transcorrente de Taxaquara (Hennies et al., 1967) em local próximo ao seu limite ocidental, situado na cidade de Piedade, São Paulo. Nessa zona de falha onde predominaram os esforços de compressão observase uma transição desde filitos não tectonizados a cataclasitos e finalmente milonitos e filonitos. Apresentam estrutura orientada com foliação proeminente e mergulho oscilando em torno da vertical $\left(70^{\circ}\right.$ a $\left.90^{\circ}\right)$.

Neste trabalho apresentam-se os resultados da seção feita transversalmente ao referido falhamento (N45W). Utilizou-se um sismógrafo de 96 canais, geofones de 40 $\mathrm{Hz}$ e fonte tipo rifle sísmico (Figura 3).

Os dados foram interpretados inicialmente pelo método convencional GRM (Palmer, 1981). A Figura 4 apresenta os gráficos das funções análise de velocidade, $t_{v}$, e análise tempo-profundidade, $t_{G}$, para os diferentes $X Y$ 's (distância entre receptores) adotados. 
Os sismogramas dos tiros direto e reverso e a respectiva seção RCS são apresentados nas Figuras 5 e 6.

O gráfico de amplitudes normalizadas da Figura 7 mostra claramente dois padrões bem distintos com limite próximo da estação 45 e que coincide com o ponto de inflexão observado na função $t_{v}$ (Figura 4). Por outro lado, a função $t_{G}$ não indica nenhuma variação significativa de profundidade, tampouco a seção RCS.

A interpretação conjunta dessas informações leva à caracterização de uma significativa mudança lateral de propriedades petrofísicas do refrator, no caso uma transição entre dois materiais cataclásticos distintos. As regiões de menores amplitudes têm maiores valores de velocidades (contraste de velocidade entre a camada superficial e o refrator) e vice-versa (Figura 8).

\section{Conclusões}

Os resultados obtidos pela simulação de um modelo geológico relativamente simples, mas que gera certa ambigüidade em interpretações convencionais da sísmica de refração rasa, foram bem satisfatórios, embora tenham sido assumidas algumas simplificações e limitações para os cálculos efetuados para os valores de amplitude das frentes de onda dos sismogramas sintéticos gerados. Esses resultados demonstraram que o novo método proposto por Palmer (2001) é rápido e robusto, trazendo além das feições estruturais do refrator suas características geológicas, sendo, portanto, de possível aplicabilidade em diversas situações em geologia e geotecnia.

Ao trabalhar com um caso real, o método mostrou um resultado consistente com o do GRM, indicando as mudanças de propriedades petrofísicas no refrator, interpretadas como mudanças na sua velocidade, uma vez que a função tempo-profundidade (que está relacionada com a profundidade do refrator) não tem variações significativas como as observadas na função velocidade.
Como um ensaio de refração rasa é efetuado para a apresentação de um resultado direto e rápido, facilitaria a análise pelo método RCS o emprego de um algoritmo que lesse simultaneamente os tempos e amplitudes das ondas em cada traço analisado. Embora as leituras dos valores de amplitude tenham sido feitas, neste projeto, pelo Seismic Unix (SU), que não possui tal ferramenta, somente a análise visual da seção final dos traços convolvidos em conjunto com as funções obtidas pelo GRM já permitiriam uma interpretação qualitativa da seção sísmica.

O método não substitui os outros existentes, mas empregado conjuntamente com o GRM, traz informações adicionais quanto às características geológicas do refrator.

\section{Agradecimentos}

Os autores agradecem a Fapesp, IAG/USP e mineração Minerfil Mineradora Ltda. pelo apoio dado para a realização desta pesquisa.

\section{Referências}

Hennies, W. T.; Hasui, Y.; Penalva, F. (1967) - O falhamento transcorrente de Taxaquara. Anais do XXI Congresso da Sociedade Brasileira de Geologia, novembro 1967, Curitiba-PR.

Palmer, D. (1981), An introduction to the generalized reciprocal method of seismic refraction interpretation. Geophysics, 46, 1508-1518

Palmer, D. (2001), Digital processing of shallow seismic refraction data with the refraction convolution section. $\mathrm{Ph}$ D Thesis, Univ. of NSW, $256 \mathrm{p}$

Werth, G. A. (1967), Method for calculating the amplitude of the refration arrival, in Musgrave, A. W., Ed., Seismic refraction prospecting: Society of Exploration Geophysicists, 119-137

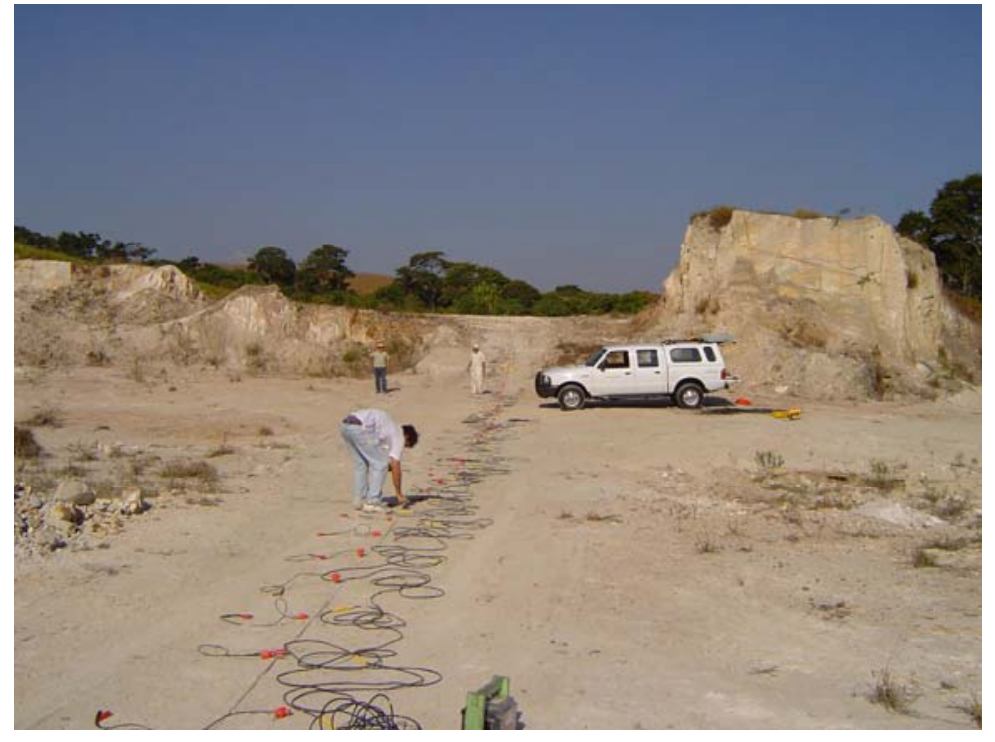

Figura 3: Local dos ensaios e linha sísmica 

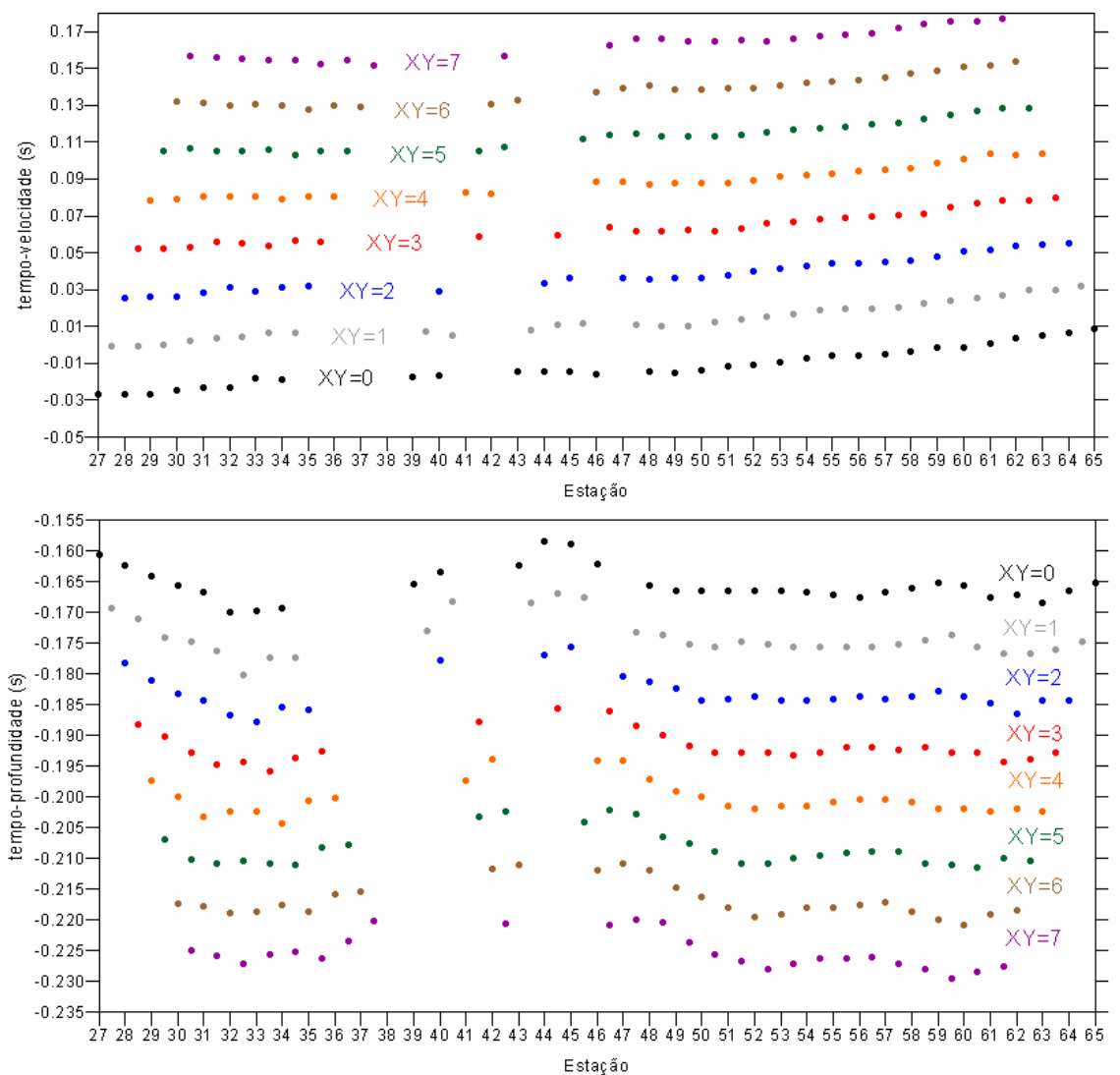

Figura 4: Gráficos das funções análise de velocidade e tempo-profundidade para os diferentes XY's adotados.
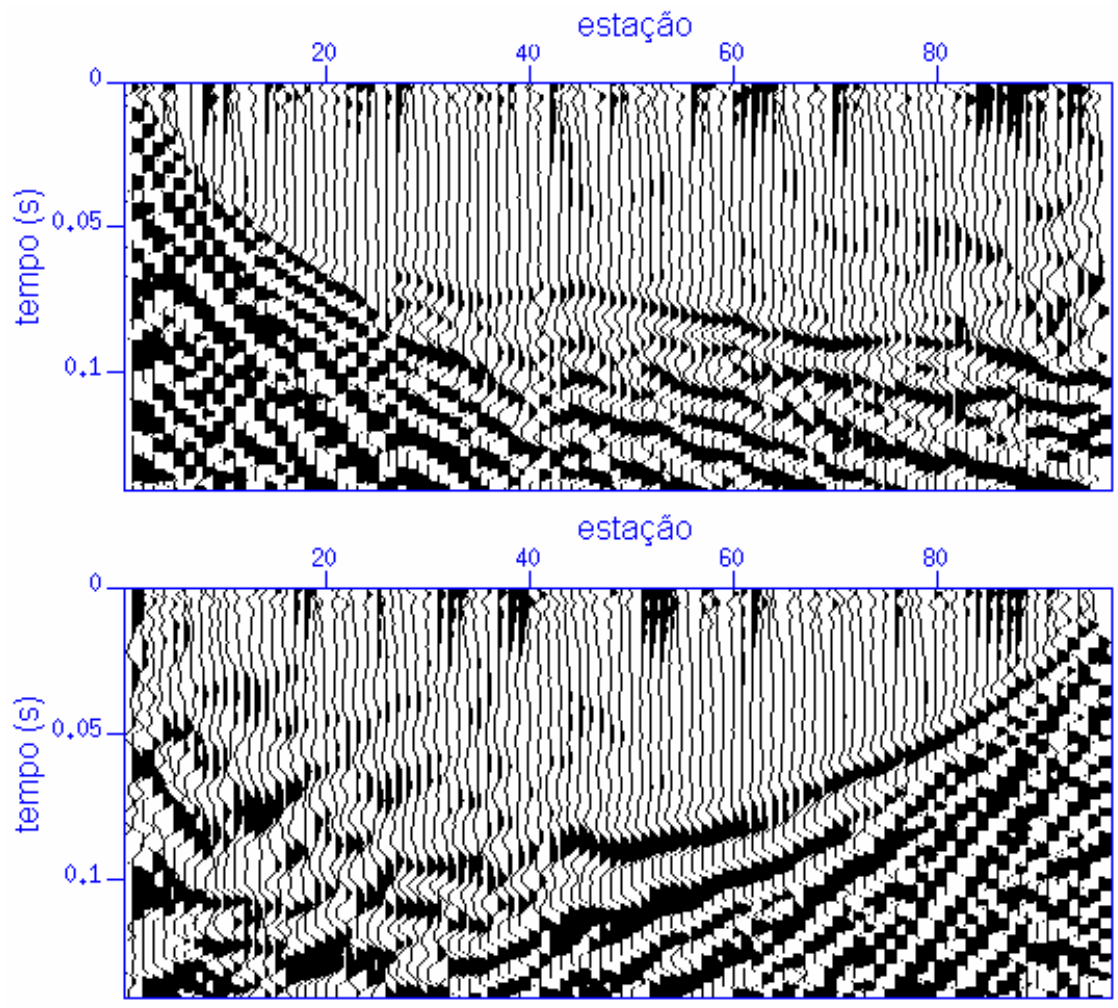

Figura 5: Sismogramas de campo (tiros direto e reverso). 


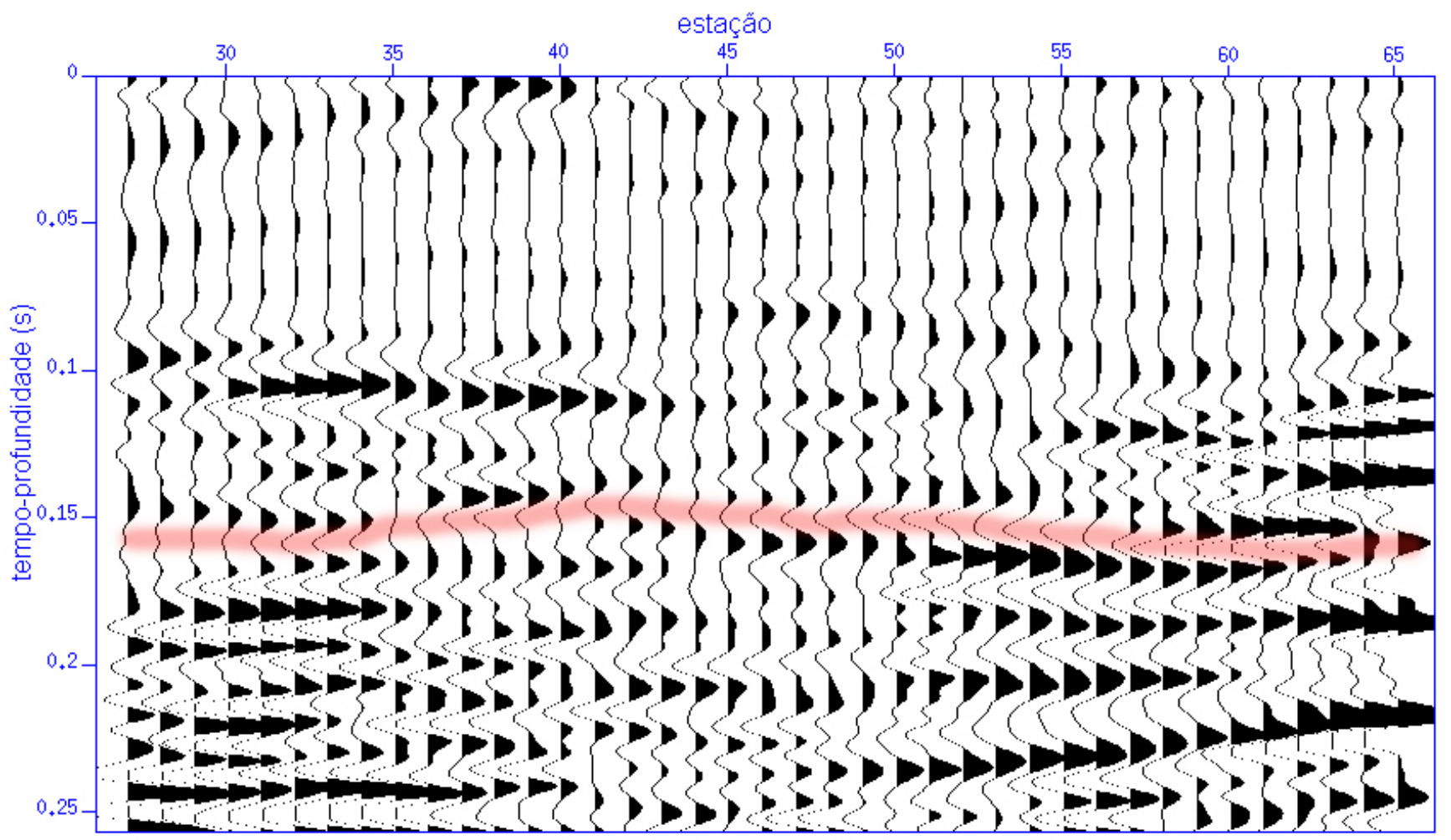

Figura 6: Seção RCS resultante da convolução dos sismogramas da Figura 5.

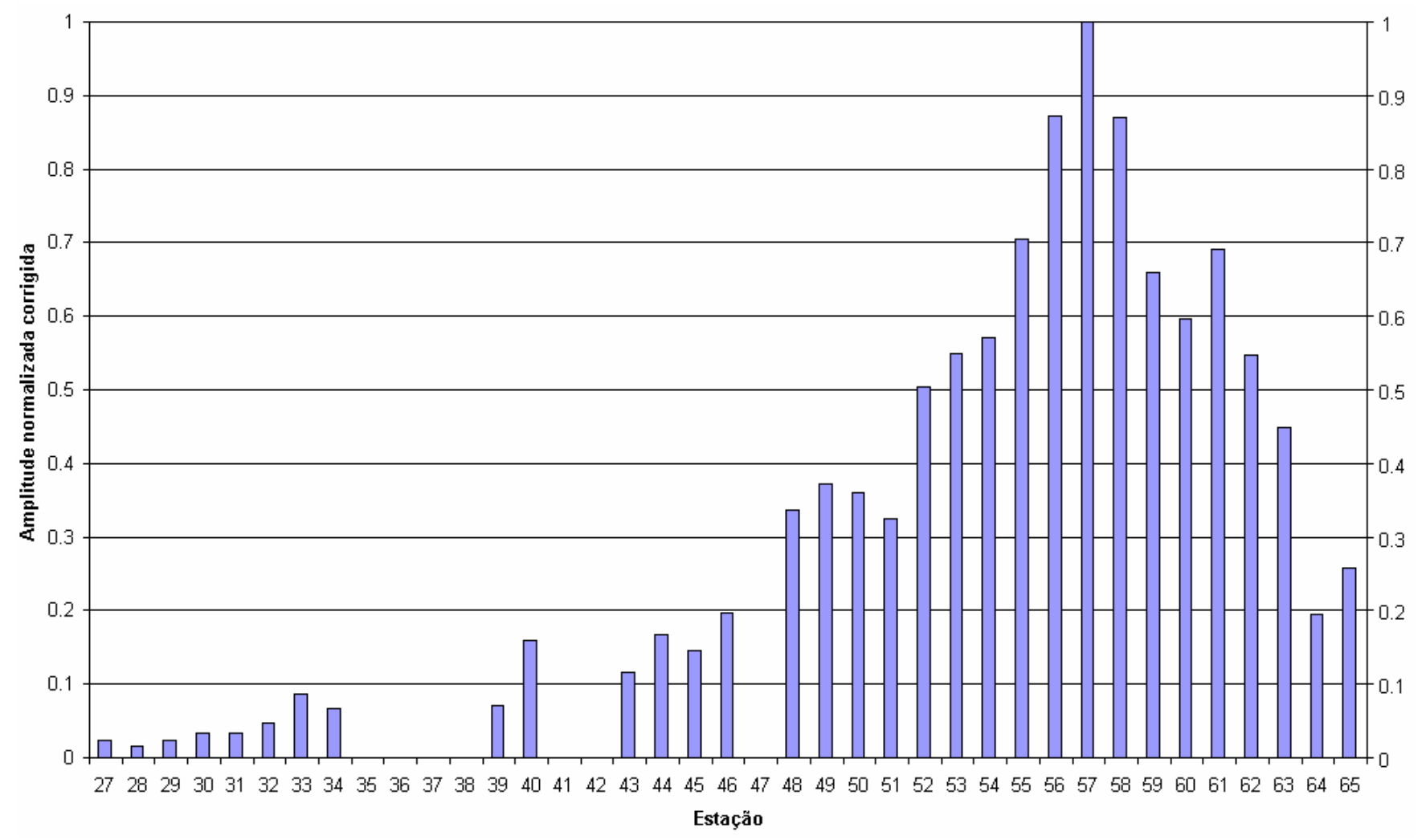

Figura 7: Amplitude normalizada dos traços convolvidos pelo RCS, corrigida pelo efeito geométrico. 


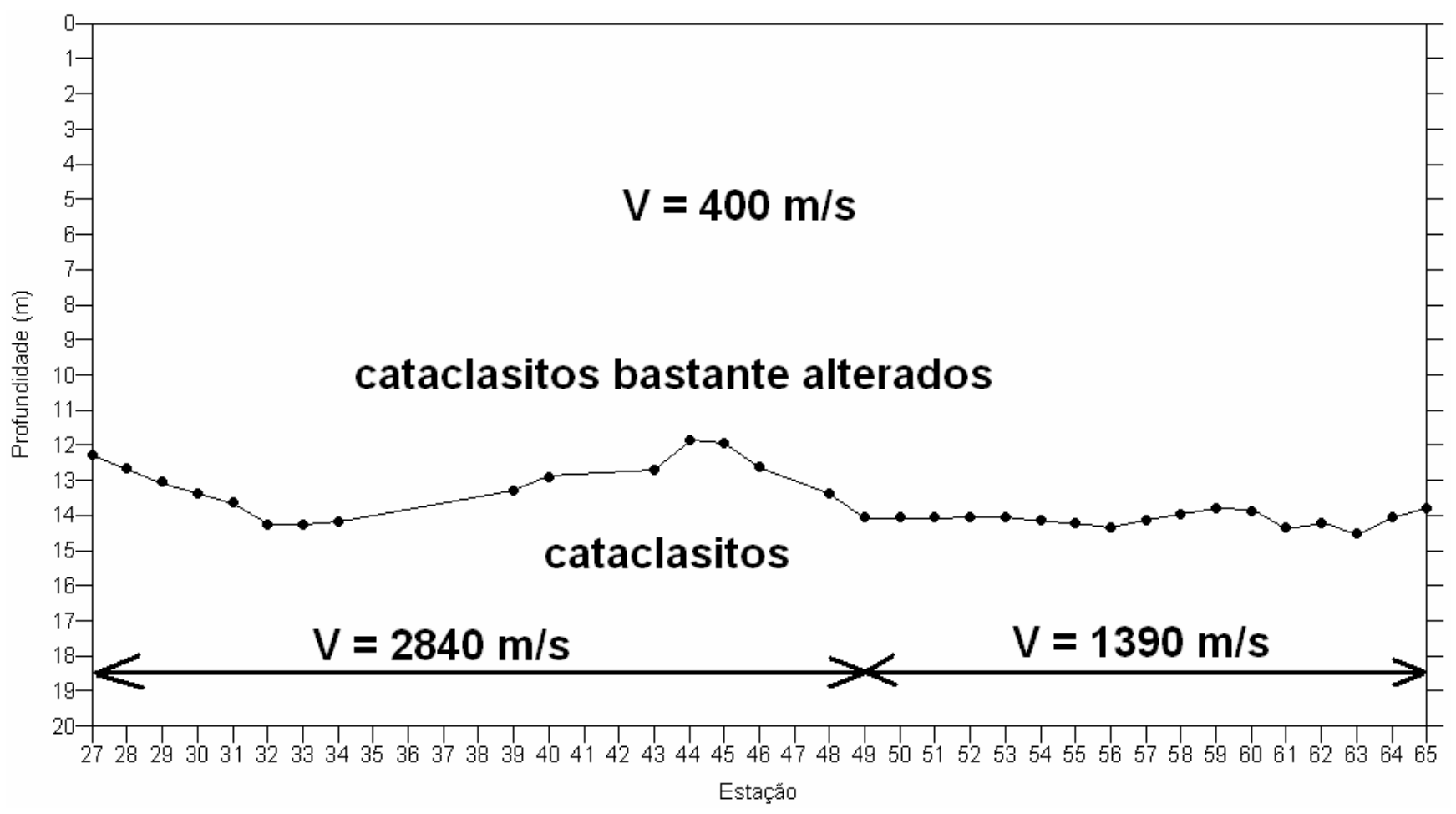

Figura 8: Seção final interpretada para o perfil normal à falha. 